International Journal of Linguistics Studies (IJLS)

ISSN: 2754-2599

DOI: $10.32996 / \mathrm{ijls}$

Journal Homepage: www.al-kindipublisher.com/index.php/ijlss

\title{
Epistemological Challenges Against Sociolinguistics
}

\author{
Iskandarsyah Siregar \\ Head of Center for Nusantara Socioculture Studies, Universitas Nasional, Jakarta, Indonesia
}

$\square$ Corresponding Author: Iskandarsyah Siregar, E-mail: regaranggi@presidency.com

\section{ARTICLE INFORMATION}

Received: 08 September 2021

Accepted: 11 October 2021

Published: 26 October 2021

DOI: 10.32996/ijls.2021.1.2.6

\section{KEYWORDS}

Sociolinguistics, Epistemology, parole

\section{ABSTRACT}

Sociolinguistics is a linguistics science that seeks to express the values of life that are revealed in language. Sociolinguistics is stuck in the study of language, which is purely empirical. This assessment can be observed when sociolinguistics only comes to the study of language, which reveals the linguistic system. It is essential to point out the other side of sociolinguistics that has not been explored, namely the aspect of language meaning. In this case, epistemology tries to challenge the existence of sociology concerning the role and function of sociolinguistics itself. Through literature study, Hermeneutics and heuristics are consistently and consistently used as the basis for the research method in this case. It can be concluded that sociolinguistics must begin to view language as a form of culture that becomes a social system and acts as a tool for human development.

\section{Introduction}

\subsection{Preliminary}

Language is an exciting entity to be studied and questioned. Its existence which is vital to civilization though often underestimated makes it necessary to decide right or wrong. Language is a means of conveying messages from articulators to auditors (Siregar, 2021, p. 54). Therefore, language becomes an essential and exciting variable to be studied and revised scientifically for the preservation and progress of civilization. For the record, the language discussed here is an agreement on morphological and phonological constructions listed in the dictionary and all symbols that contain signs and meanings in civilization.

Linguistics is the most effective and efficient tool for studying languages. Linguistics is empirically proven to be effective and efficient in answering various problems of civilization. One of the most popular branches of microlinguistics is Sociolinguistics. Sociolinguistics is an interdisciplinary technology that studies language concerning the communication ecosystem in the community of civilizations. As an object in sociolinguistics, language is not seen or approached as a mere lexical arrangement but is seen or approached as a means of interaction or communication in society.

Such sociolinguistic characteristics show an attempt to go beyond the primary science, namely structural linguistics. It can be said. Sociolinguistics is a science of language that seeks to express the values of life revealed in language.

Sociolinguistics is stuck in the study of language, which is purely empirical. This assessment can be observed when sociolinguistics only comes to the study of language, which reveals the linguistic system.

Based on this fact, the writer feels the need to raise the other side of sociolinguistics that has not been explored, namely the aspect of language meaning. Because, in essence, humans communicate with each other to convey messages in the form of meaning, which is automatic, containing the value in it. When humans converse within themselves to contemplate, language will lead them to think and make decisions for each problem. Therefore, it is a mistake if language is only studied based on practical aspects of mere sound and form.

Scientific objectivity will be achieved when the ontology and axiology aspects of science do not overlap. Therefore, in philosophical research, a 'heuristic' method is developed, which is a method to find and develop new scientific methods, even in philosophy

Copyright: (C) 2021 the Author(s). This article is an open access article distributed under the terms and conditions of the Creative Commons Attribution (CC-BY) 4.0 license (https://creativecommons.org/licenses/by/4.0/). Published by Al-Kindi Centre for Research and Development, London, United Kingdom. 
itself (Kaelan, 2004. p. 96). The consequence of applying this method is the search for alternatives to the scientific paradigm. Thus, the theoretical imbalance in science can be corrected to be solid when applied in research.

The difference between langue and parole will lead the author to search for research objects, methods, and systems and the basics of truth used in sociolinguistic research when examining aspects of language meaning. This search, of course, must be preceded by placing the sociolinguistic definition back by the appropriate object of research material based on the difference in definitions between langue and parole.

Epistemology is essentially a philosophical study of the nature, origin, and limits of human knowledge. Alternatively, in other words, epistemology is a branch of philosophy that deals with knowledge. It is sometimes referred to as a theory of knowledge. In this case, epistemology tries to challenge the existence of Sociology concerning the role and function of Sociolinguistics itself.

\section{Research methods}

The research that forms the basis for writing this scientific article begins with a study with literature observations. Of course, this must be done in opening up horizons and collecting as much literature data as possible to serve as a basis for research. Nevertheless, that is not enough. Comparative analysis of triangulation between literary theory and factual empiricism is the key to discussion and conclusion. The power of logical argumentation is the basis of victory in research that tries to formulate an idea against an idea.

In summary, the research method used in this case is to collect conservative ideas relevant to the research problem, seek comparisons from species of ideas and empirical data, and then analyze each relativity and associated distortion. Hermeneutics and heuristics are consistently used as the basis for the research method in this case.

\section{Results and Discussions}

In essence, Epistemology always works side by side and collaborates with Ontology and Axiology as a reliable construction of philosophical studies to use. So, to explore, discuss, and conclude the problems, in this case, we must carry out this collaborative work systematically as well.

The concept of the nature of language for humans proposed by structural linguists, namely langue, actually failed when Saussure formulated the concept. This fact is reminiscent of Saussure's attempt to separate language from humans with the rationale of finding general laws. With this generality principle, Saussure considers language will be worthy of scientific study.

Language, if observed causally, will never be separated from humans forever. Therefore, studying the language by first removing the human element in it is a mistake. On this basis, a researcher will be disappointed if he tries or even defines language research methods as positivistic and quantitative research.

However, Saussure's findings on parole have similar elements as proposed by Ludwig Wittgenstein as an ordinary language. This material object led Wittgenstein to produce his famous work entitled Philosophical Investigation.

Wittgenstein further developed Moore's thinking about ordinary languages by proposing language games. According to Wittgenstein, based on the fact that humans use ordinary language in everyday life in a variety of activities and contexts. Each language used has its own rules. Therefore, idiom analysis is carried out not to find universal logical truths but to find out the truths of using language according to their respective rules.

Awareness of the fact that everyday life is complex, including various fields of life, language also includes various uses, and the sentences vary. The number of languages is constantly growing and not fixed, so that new types of languages always appear which are alternated and the old ones are forgotten (Kaelan 2006, p. 73). However, that does not mean that the various types of use do not have rules. The term grammar game used by Wittgenstein shows this affirmation. This was emphasized by Wittgenstein like a chess game, each of which has its role. Only by knowing and understanding the rules of the chess game will we think three times (think three moves ahead) before moving chess pieces. If we find the application of this rule on the chessboard, we will feel amazed and understand the purpose and purpose of a rule.

Understanding the grammar of this language game means that in this life, humans find various kinds of games, such as volleyball, soccer, tennis, and so on, each of which has its own rules of the game. Thus, grammar game shows us that every form of language game has its own rules that cannot be mixed with other (various) rules. Scientific variety, for example, has its own rules of the game, which have implications for the provisions that the scientific community must obey. The use of language in a scientific context cannot be confused with language in a relaxed manner because the casual variety has its own rules. Chaos will arise when we apply the rules of one language game to another. Therefore, it is impossible to determine a general rule of language game that applies in various contexts of human life. As emphasized by Kaelan, Wittgenstein's thoughts have a similar attitude as stated by Agustina and Chair (2004, p. 191), as in the case of the mention of standard language, namely naming standard naming one of the varieties that exist in a language. Therefore, from the outset, it is necessary to explain that the more appropriate naming is 
standard language variety or standard language variety, and not just standard language. So, naming Indonesian as the national, official, or language of unity is naming the entire Indonesian language as a langue with all its varieties and variations. Meanwhile, standard Indonesian (variety) is only one variety of the many varieties of Indonesian that exist, which are only used in official state situations.

The summary of the various thoughts above leads the writer to the conclusion that Saussure's thought that parole is not suitable as a material object for language research can be corrected with the grammar game theory of Wittgenstein. Because langue is not something that is the same for all but varies in each individual. After this understanding is "straightened," then it can be seen that in langue, language is the activity of speakers, langue is a product that individuals actively record. Langue is an integrated part with language, inside and outside the individual, which independently makes it possible to create or change it. Langue exists as a result of some past, present, and possibly future contract between the members of society. After all, the individual needs to recognize the game's rules; a child can only live little by little. Langue is something that is integrated with a human who appears in parole. Langue, along with parole, is a concrete object, which is very beneficial for its study (Saussure 1993, p. 81).

Sociolinguistics, a linguistic science interdisciplinary with sociology, which examines social factors related to interaction or communication in society, actually has an excellent opportunity to play its role as a valuable science for enriching the understanding of human life that requires values.

According to Koentjaraningrat (Kaelan 2005, p. 49), culture is divided into three types:

1. The form of culture is valued, namely ideas, thoughts, concepts, and human thoughts. The form of culture is abstract, cannot be sensed. This form is often referred to as a cultural system;

2. the form of culture in the form of a complex of activities, namely in the form of human activities that interact with each other so that they are concrete and can be sensed, and this form is referred to as a social system;

3. the form of culture in the form of cultural objects, namely the results of human culture in the form of cultural objects that are also concrete.

Sociolinguistic research, according to JA Fishman (Agustina and Chaer 2004, p. 5), is a study that is more related to the details of actual language use, such as descriptions of patterns of language/dialect usage in specific fields, choices of language/dialect usage made speaker, topic, and setting of the conversation. However, according to the author, sociolinguistics will be more meaningful if it stops at describing patterns of language use or use. Furthermore, suppose it is associated with the second type of cultural form, namely the form of culture in complex activities (social systems). In that case, the sociolinguistic study or object of sociolinguistic research material that the author offers is a form of culture as a social system through the use of language expressions in society. With the material object of this research, it will be revealed or found tendencies of specific philosophical values in the complex activities of society, for example, the philosophy of hedonism, feminism, materialism, and philosophical values.

The development of science and technology that is increasing rapidly lately automatically affects communication between humans in a social system. Therefore, a change in society will also bring about a change in the orientation of human life, both concerning orientation to the value of human work, orientation to the value of time in human life, orientation to the value of human relations in community life, and orientation to the value of human relations. with the natural environment. This orientation towards philosophical values that develop in a particular society and at a specific time is also a material object of philosophical research, and by itself, this research is interdisciplinary with social research (Kaelan, 2005, p. 52). In the author's opinion, this research can also be carried out by sociolinguistics, considering that research on material objects like this is not only at the level of causality or correlative but also qualitative research models to interpretive philosophical values that develop in society. Through parole, which the author has corrected with the grammar game theory of Wittgenstein, language produces and shows human culture. The concept of language games provides a philosophical basis that the essence of language is its use in human life which is complex, spontaneous, unlimited, and varied (Wittgenstein 1983, p. 23; Kaelan 2006, p. 145-146). Still, according to Wittgenstein, meaning is the value contained in the expression of language is found in human life because, in principle, the language used by humans in communicating is to express a meaning that is a value of life (Kaelan, 2006, p. 155).

After obtaining the ontological legitimacy of parole and obtaining the object of research material for sociolinguistics, the next author will direct the search to the epistemological aspect of sociolinguistics.

According to structuralists, language as a source of knowledge is commensurate with other natural phenomena so that verification can be applied in the natural sciences. The epistemological model of structuralism appears to have natural, empirical characteristics and tends to build a theory.

The development of sociolinguistics that considers external aspects in the form of studies of things or factors outside of language (syntax, morphology, phonology, etc.) related to the use of language is a step forward and is a paradigmatic revolution in the field of linguistics. Because, thus, sociolinguistics has tried to approach the nature of language, which is essentially the value of life. 
However, epistemologically there is still an attachment to structural linguistics, especially concerning the epistemology of language. This fact appears explicitly with the requirement to study the external study of language, and a researcher must first engage in the internal study of linguistics (Agustina and Chaer, 2004: 2). Sociolinguistic studies that have been carried out so far relate to the details of language use that describe patterns of language/dialect usage in a particular culture, the speaker's choice of language/dialect usage, topics, and the conversation background. The process of detailing and describing usage patterns requires structural linguistic abilities such as syntax and sign systems, considering that structural linguistics studies language using this aspect.

Structural and descriptive aspects cannot be separated from sociolinguistic studies. However, the dimension of language, according to Wittgenstein, is much broader than that. Wittgenstein emphasizes the word's meaning, not on the justification of language as a sign system but the nature of its meaning in its use in human life. The unlimited context of human life causes the meaning in the use of the language to be unlimited. Every aspect of life uses meaning according to its own game (Kaelan, 2004, p. 173).

Language expressions such as giving orders and obeying them, describing the appearance of an object, describing, reporting an incident, acting, speculating about events, and reading stories, are the use of language in various kinds of human life (Wittgenstein, 1983, p. 23; Kaelan, 2004, 2004). p. 174). If the use of language in various contexts of human life has different meanings, then in every language game, several rules must be met so that in the use of that language, there can be clear communication about a language meaning (Ginn, 1997, p. 75; Kaelan, 2004, p. 175). The basic assumption of Wittgenstein, which suggests ordinary language in grammar games, thus, has similar elements as in parole, which the author has previously strengthened by concluding that langue and parole are integrated, and each cannot be separated from each other just like that from humans.

Sociolinguistics, in other aspects, still tends to develop normative aspects as is done by structural linguistics, such as verbal repertoire, speech communities, deficit hypothesis, etc. If sociolinguistic epistemology works like this, it can be said that sociolinguistic studies fall into nomothetic science.

Linguistics, including sociolinguistics, is a science related to humans and their lives that can be studied through language expressions. Sociolinguistics, thus, includes the science of humanity. Consequently, the methods developed in the sciences should also be related to the human aspect.

The method offered by Wittgenstein in studying the values of human life conveyed through language is called grammatical inquiry. The method of grammatical investigation developed by Wittgenstein does not start on a system of using language as a sign system but is determined by the language itself. Wittgenstein believes that by using this method, he is trying to change a belief that has been formed in the use of language, which gives a grammatical systematization character that regulates the use of language in human life because, in this way, it is not humans who use language to communicate in various fields of life. Instead, humans are controlled by a strict language structure.

Wittgenstein's goals in the grammatical investigation are of two kinds. First, it uses to develop and make language realized by humans between philosophically and conceptually reflective ideas about the nature of language use with the factual reality of language functioning its use in human life. Second, Wittgenstein uses this method to draw human attention to the differences in the use of language in various fields of life and the specifications that characterize the various uses of each in every context of human life.

Wittgenstein asserts that in developing the method of grammatical investigation, the subject is actively involved in the object because what is discussed is related to qualitative phenomena, mental, emotional, feeling, and human expression through language. These things can only be analyzed by investigating the use of language in human life, which is carried out by explaining, describing, and objectively describing the phenomenon. This principle is the basis of Wittgenstein's foothold in grammatical investigations that require the subject to be directly involved because the phenomenon of language is related to human life, which is qualitative.

Sociolinguistics is a field of empirical science related to material objects that are dual and qualitative. Consequently, when conducting scientific investigations, the field of sociolinguistics is not enough to only develop its studies based on structural, rational, and mathematical empirical aspects. The sociolinguistic material object that the author has put forward is the form of culture as a social system through the use of language expressions in society. It requires methodical elements in descriptive methods used in scientific research related to human aspects such as analytical methods, verstehen methods (understanding), interpretation method, hermeneutic method, language analytical method, abstraction method, historical method, comparative method, inductive method, and heuristic method.

The science journey concerning the relationship between the need or not of value in scientific research has two different views. A school argues that science is essentially value-free, 'value-free,' meaning no relationship between science and value (Kaelan, 2006, p. 154). In contrast to this view, the notion of phenomenology, including natural and humanistic sciences, argues that as long as 
humans are interested in science, science is value bound. According to this understanding, our recognition is perspective, how and from where we know and influence what we know. Theory and facts are determined by values (Kaelan, 2006, p. 154).

It cannot be denied that ontologically, language has two dimensions, namely empirical and non-empirical dimensions. Language expressions in the form of non-empirical, in the form of meaning, are values in life. According to Wittgenstein, meaning which is the value contained in the expression of language is found in human life, because in principle, language is used by humans in communicating to express a meaning which is a value of life.

Sociolinguistics itself only understands the value of language based on its empirical aspects. This fact can be observed when sociolinguistics only relies on assessing the linguistic system of a language in one nation among other nations. Meanwhile, the meanings and values in human life expressed through language are unlimited and varied. For example, if we use the word 'Indonesia' and want to know its meaning, we must know the values of life-related to the use of the word. To express the meaning contained in the expression of the word, we must know the value of life concerning the word, for example, location, territory, population, people, and flag, which are related to the rules for using the word. The word 'Indonesia,' which is used as a context of the song 'Indonesia Raya,' contains the value of 'my homeland,' 'the land where my blood is spilled,' 'the land where the Ind onesian people live and make a living, as well as contain the meaning of willingness for every nation to make sacrifices.

The meaning of language is not found in language or language speakers but is found in human life itself. Therefore, according to Wittgenstein, observations must be made on human life concerning the rules for using language to examine the meaning. Each context of language use has its own rules, and the rules and their use in human life will find the meaning of language.

Thus, it has produced findings based on a search on sociolinguistics that strengthens the non-empirical aspect of the language, namely meaning. The object of sociolinguistic research material related to the non-empirical aspects of language that the author puts forward is the manifestation of culture as a social system through language expressions in society. Meanwhile, qualitative research methods are used for the epistemological aspect of research on sociolinguistic material objects that the authors have found. Meanwhile, for language axiology, the writer suggests the importance of exploring the values of life to understand every expression of the meaning of language.

\section{Conclusion}

The advantage of the study of material objects that the authors put forward, namely the manifestation of culture as a social system through language expressions in society, is that a sociolinguistic researcher will have a significant role in human development. Because, thus, the results of the sociolinguistic research of this model will reveal to the public about a particular philosophical view reflected in social communication, and usually in the form of specific values that become the tendency of certain people's philosophy of life. This material object is not limited by a particular time and is dynamic. In a specific social system, a tendency to certain philosophical values can be found, for example, the philosophy of hedonism, feminism, materialism, and specific philosophical values.

Parole's position, henceforth, has been firmly recognized as the basis for scientific language research. Because, referring to the characteristics of parole, humans who have a causal relationship with language are indeed diverse, unique, complex, and cannot be tested based on positivistic principles, but must be understood, interpreted, and interpreted because they involve understanding, concepts, values, and characteristics. Characteristics are inherent holistically to the data concerning various aspects that may exist.

Sociolinguistics must start or even return to examine linguistic problems in civilization which contains humans, symbols, and meanings. The value poverty of Sociolinguistics caused by too lazy and rigid usage must be ended immediately. For this reason, Sociolinguistics is obliged to collaborate with other humanities disciplines to find the most effective and efficient problem-solving methods and solutions.

\section{References}

[1] Agustina, L \& Chaer, A. (2004). Early Introduction Sociolinguistics. Jakarta: PT. Rhineka Cipta.

[2] Cook, V. J., \& Wei, L. (2016). The Cambridge handbook of linguistic multicompetence (eds). Cambridge: Cambridge University Press.

[3] Kaelan A. (2004). Analytical Philosophy According to Ludwig Wittgenstein. Yogyakarta: Paradigm.

[4] Kaelan A. (2005). Qualitative Research Methods in Philosophy. Yogyakarta: Paradigm.

[5] Kaelan A. (2006). Analytical Philosophy of Language and Its Influence on Science. Yogyakarta: Paradigm.

[6] Muhadjir, N. (1996). Qualitative Research Methodology. Yogyakarta: Rake Sarasin.

[7] Musgrave, S. (2014). Language shift and language maintenance in Indonesia. In Language, Education, and Nation-building (pp. 87-105). Palgrave Macmillan, London.

[8] Osoba, B. K., \& Osoba, G. A. (2014). Code-mixing in selected plays of the new generation Yorùbá playwrights. American Research Institute for Policy Development.

[9] Octavita, R. \& A. (2016). Code-Switching and Code Mixing in Novel the Devil Wears Prada by Lauren Weisberger: A Sociolinguistic Study.

[10] Saussure, F. (1993). Introduction to General Linguistics. (trans.) Rahayu S. Hidayat. Yogyakarta: Gadjah Mada University Press. 
[11] Siregar, I. (2021). Verbal Communication of Schizophrenic Patients Due to Neurotransmitter Distortion. QALAMUNA: Jurnal Pendidikan, Sosial, Dan Agama, 13(2), 543-556. https://doi.org/10.37680/qalamuna.v13i2.1037

[12] Siregar, I. (2020). Exploration and Implementation of the Cultural System as a Solution to National and State Problems. http://repository.unas.ac.id/id/eprint/811

[13] Siregar, I. (2021). Analysis of Betawi Language Interference on the Morphology of Adolescent Speech in Jakarta. Journal of Humanities and Social Sciences Studies, 3(8), 54-60. http://doi.org/10.32996/jhsss.2021.3.8.7

[14] Wittgenstein, L. (1983). Philosophical Investigations. (Trans.) G.E.M. Anscombe. London: Basil Blackwell. 